\title{
Neither Logical Empiricism nor Vitalism, but Organicism: What the Philosophy of Biology Was
}

\author{
By: Daniel Nicholson \& Richard Gawne
}

Like a slow-burning story of triumph, the canonical narrative of the history of contemporary philosophy of biology tells the tale of a subfield emerging out of the smoldering ashes of logical empiricist philosophy of science, and the wreckage of an equally futile vitalistic program that preceded it. Most logical empiricists scoffed at the life sciences, and those who did deem it worthwhile to explore the biological realm produced nothing of value. The logical empiricists failed because their project was a prescriptive enterprise whose primary mandate was to bring increased rigour to biology by importing methodological protocols from the physical sciences. Vitalists of the early twentieth century were not stricken with physics-envy, but the animating forces and other metaphysical phantasms they conjured into existence to ward off the threat of reductionism were at least as ill-conceived as anything produced by the logical empiricists. Practitioners associated with the aforementioned schools failed to seriously engage with the science that allegedly inspired their musings, and as a consequence, the philosophy of biology languished in a state of futility for much of the twentieth century.

Things began to change sometime in the late 1960s and early 1970s, when the textbooks by Michael Ruse (1973) and David Hull (1974), together with a series of articles by Ken Schaffner (1967; 1969a; 1969b) and Bill Wimsatt (1970; 1972a; 1972b), found their way into print. These efforts are regularly identified as the first significant contributions to modern philosophy of biology. Unlike the logical empiricists and vitalists of previous decades, these thinkers focused on problems internal to biology, and it is this unapologetic emphasis on contemporary science which facilitated their success. Over time, replies were published, new topics were examined, and the prejudices the philosophical community formerly harboured against the life sciences faded away as the philosophy of biology grew into the recognized field of specialization that it is today.

For over three decades, the above account of the discipline's history has circulated within the community (see, e.g., Sober 1984: 6-7, Brandon 1996: xii-xiii, Kitcher 2003: xii, Matthen and Stephens 2007: xi-xii). Although details occasionally vary, it is widely agreed that the philosophy of biology as a discipline was born in the last third of the twentieth century, following years of neglect and a host of misinformed false-starts. No one has done as much to popularize this account as two of the story's lead characters: Michael Ruse and David Hull. Over the years, Ruse has been particularly vocal about the pivotal role that he and Hull played in the establishment of the discipline, noting that 'David Hull is the father of modern studies of biology from a philosophical viewpoint' (2008: 4), and crediting himself on repeated occasions as "one of the founders of contemporary philosophy of biology" (2006: 37). (See also Ruse 1997: 120; Hull and Ruse 2007: xix-xx; Takacs and Ruse 2013: 5-6)

Hull and Ruse have also done a great deal to spread the idea that philosophical work on biology prior to the 1970s was completely devoid of value. Consider, for instance, the following passage from Ruse's Philosophy of Biology Today:

[I]n this century particularly, the philosophy of science has become almost a subdiscipline in itself. But this does not include the philosophy of biology - at least, it did not until very recently [...] [P]hilosophers of science in the twentieth century have focused mainly on the physical sciences, and any spare effort has tended to be directed toward the social sciences. What little attention has been paid to biology has been generally directed to one extreme or another. At one end of the spectrum we have those who 
were overly impressed by the turn-of-the-century formalisms of the logicians and mathematicians, and who wanted to do likewise for biology. Since they-especially their leader J. H. Woodger-were simultaneously empiricists of the most naively dogmatic kind, their efforts tended to go unread. At the other end of the spectrum we have those who feared and loathed materialism, and who were determined to prove that an understanding of organisms demands reference to vital forces or spiritselans vitaux or entelechies-forever beyond the grasp of conventional science. (Ruse 1988: 1-2) The purpose of this paper is to set the record straight about the history of the field. Through a combination of historical and philosophical analysis, we argue that the current account of what the philosophy of biology was prior to the 1970s, as exemplified by Ruse in the above quote, is almost entirely false. We do this by suggesting that the most important tradition within early philosophy of biology - the organicist school that flourished in both Europe and the United States in the interwar period-had no direct connection to either logical empiricism or vitalism. We also demonstrate the continuity of the organicist literature with the contemporary debates in order to cast doubt on the claim that nothing of value was produced during the first half of the twentieth century.

To be clear, this is not simply a priority dispute about what deserves to be credited as 'philosophy of biology'. It is an attempt to make contemporary philosophers of biology aware of a huge body of literature containing insights from philosophically-minded biologists and biologically-minded philosophers whose contributions have been almost completely neglected for nearly a century. Contemporary philosophers of biology should be standing on the shoulders of these giants, not their faces. 